\title{
Informed Consent of Living Kidney Donors: Pitfalls and Best Practice
}

\author{
Rebecca E. Hays
}

Published online: 20 January 2015

(C) Springer International Publishing AG 2015

\begin{abstract}
Informed consent is clearly considered the ethical bedrock fundamental to living organ donation, a procedure lacking medical benefits for its participants. Recent guidelines have focused on strengthening content components of living kidney donor informed consent, including Organ Procurement and Transplantation Network (OPTN)/United Network for Organ Sharing (UNOS) policies that prescribe key components, and integration of the Independent Living Donor Advocate (ILDA), as mandated by Centers for Medicare and Medicaid Services (CMS) and the OPTN/UNOS. The European Union member states' Working Group on Living Donation provided recommendations for care standardization in the "Toolbox Living Kidney Donation," including integration of an independent clinician advocate. However, even with these changes, studies suggest inconsistency in informed consent elements across transplant programs, and retrospective studies show that although the vast majority of living donors (LDs) reflect back positively on the experience of donation, some describe lacking complete knowledge of risks (or process) before donation. Processes to assure achievement of informed consent remain in the purview of individual transplant centers to implement and measure. Herein, methods to assess prospective LD intentionality, voluntariness, and understanding of risks/benefits are described, with promising techniques highlighted and recommendations for best practice outlined. Specific clinical challenges are addressed, including ambivalence, risk of secondary gain, and difficulty integrating understanding of risks. Finally, additional content elements are proposed to improve validity of informed consent in specific clinical circumstances.
\end{abstract}

This article is part of the Topical Collection on Live Kidney Donation

R. E. Hays $(\bowtie)$

Transplant Clinic, University of Wisconsin Hospital and Clinics, 600

Highland Ave F8-139, Madison, WI 53792-1735, USA

e-mail: rhays@uwhealth.org
Keywords Living donation · Kidney donation · Kidney donor $\cdot$ Consent $\cdot$ Donor education $\cdot$ Disparities $\cdot$ Live donor kidney transplantation

\section{Introduction: Basics of Informed Consent in Living Donation}

Informed consent occurs when a competent person makes an autonomous choice about whether or not to access medical treatment, armed with adequate information and understanding regarding risks, benefits, and expected outcomes [1]. The process is often described as reciprocal, in which clinician and patient share information disclosure, processing, and decision making. The patient's ultimate intention to proceed, understanding of process and benefits, and free will to decide are fundamental. That said, in any clinical practice setting, these factors present along a continuum between clarity and confusion [2]

Informed consent within the context of living organ donation has added necessary components, most notably the strong establishment of the donor's autonomous desire to proceed, given that $\mathrm{s} /$ he gains no medical benefits from donation. In addition, in the shared transaction of living donor (LD) transplantation (LDT), the prospective donor must gain an understanding of the procedure's expected outcomes for donor and recipient $[3,4 \bullet \bullet]$. These tenets have been present since the beginning of LDT. Prior to the first LD transplant case, surgeon Joseph Murray assembled a separate team to care for the prospective donor and to facilitate thorough and unbiased risk assessment and education [5, 6]. Gordon summarized components beautifully, as follows:

"The principle of respect for persons requires that potential living donors (LDs) be competent and informed, and comprehend the risks to themselves of undergoing 
the procedure, as well as the risks, benefits and alternatives available to the recipient. Further, potential LDs must be willing to donate and be free from undue pressure to consent to the procedure. ...Moreover, respect for autonomy means that LDs have the right to determine how much risk they are willing to accept, and conversely, that LDs (and the recipients) have the right to refuse the donation." $[4 \cdot \bullet]$

\section{Regulatory Guidance}

Specific elements of informed consent for LDs have gained focus over time in consensus conferences outlining best practice, and have eventually been integrated into regulatory guidelines to promote strengthened processes, and for standardized elements of disclosure and education. The 2000 Consensus Statement on the Live Organ Donor, as well as the Declaration of Istanbul, identified LD voluntary status as essential to informed consent, and affirmed that a living kidney donor should understand treatment options for the recipient [7-9]. A 2011 Joint Societies consensus conference on LD long-term follow-up reinforced that donors must understand personal medical risks (short- and long-term) associated with the procedure [10].

In 2007, LD consent guidelines were regulated via the Centers for Medicare and Medicaid Services (CMS) Conditions for Transplant Center Participation and reinforced in Organ Procurement and Transplantation Network (OPTN) care requirements $[11,12,13 \bullet \bullet]$. These policies also mandated the implementation of an Independent Living Donor Advocate (ILDA), or an ILDA team (IDAT), defining their function as a professional independent of recipient care and therefore positioned to assess LD readiness with reduced risk (or appearance) of conflict of interest, with OPTN subsequently requiring center-specific protocols. Later, OPTN/United Network for Organ Sharing (UNOS) LD informed consent policies, released in 2013 and revised in 2014, further outlined content elements, if not processes or assessment methods, for LD consent $[13 \bullet \bullet, 14]$. The 2013 OPTN/UNOS policy also outlined that potential LDs must consent to donor evaluation separately from the consent to the procedure itself [13••].

\section{Range of Practices}

In practice to date, $\mathrm{LD}$ informed consent processes have been shown to vary widely across transplant programs in the USA and worldwide, with discrepancies noted in standards, consis-

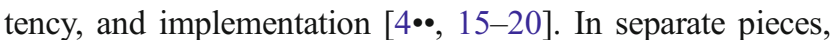
both Gordon and Rodrigue et al. identified significant 'variability and deficiencies' in the consent process across the spectrum of LD care $[4 \cdot \bullet, 15]$. Though these studies reviewed care practices prior to implementation of OPTN LD consent policy requirements, concerns raised about variability in quality of informed consent process continue to be valid. In a 2013 survey of US transplant program consent processes, Thiessen et al. found that although nearly all centers obtain written consent for evaluation from LDs, most forms lack elements required by CMS or OPTN. Specifically, elements regarding disclosure of recipient health or transplant waitlist status were often missing; other items (payment for follow-up care; risk of donor medical or psychosocial complications) were often ambiguous at best [19]. As the practice surveys by Steel et al. show, implementation of the ILDA role has varied widely as well, with ambiguity about use of the role in provision of informed consent, and in the degree to which the ILDA assessment is a component of donor candidacy [20, 21]. OPTN policy was intentionally not proscriptive about ILDA qualifications and training, pending (needed) data informing best practice. Meantime, the American Society for Transplantation Living Donor Community of Practice, in an ILDA guidance document currently in press, offered recommendations for skill sets and training [22]. In the 2014 "Toolbox Living Kidney Donation," the European Union member states' Working Group on Living Donation included recommendations for continuity in donor consent elements across member states, including provision for an independent clinician advocate in donor care [23].

\section{Methods of Assessing Voluntary Status-Intentionality}

Clearly, all living organ donors must be willing volunteers. Lacking desire to proceed is a straightforward contraindication to living organ donation [17]. However, sustained ambivalence and experience of 'pressure' (internal and external) around organ donation decision making is not uncommon [17, 24, 25]. For the purposes of LD candidacy, 'not deciding' about donation must be the same as 'deciding not to' proceed, a crucial standard to communicate to the profoundly ambivalent potential donor, who has not decided to proceed, but who also has not elected to close out the donation process.

In best practice, transplant programs employ various strategies to assist prospective donors struggling with ambivalence, including a 'cooling off period' [25, 16, 17], a 'scaling system' of readiness, referral for counseling/support, and, most recently by Dew et al., use of motivational interviewing approaches [24, 25]. Of note, literature suggests that donors who describe ambivalence at the time of donation are at higher risk for a poor psychosocial outcome [24-26]. Best practice explores the prospective donor's readiness, or stage of decision making, as a process: the psychosocial provider (and/or the ILDA) conducts repeat assessment of the prospective donor's desire to proceed after s/he has completed medical 
evaluation, and been educated about individualized risk profile and LDT expected outcomes [25].

\section{Pressured Decision Making}

Contemplation of living donation is commonly affected by feelings of pressure and obligation, felt internally and/or imposed externally. Valapour et al. found that $40 \%$ of surveyed donors felt decision-making pressure $[2,17]$. These feelings may be identified positively, as in chosen role or aspirational identity; they may also be felt internally as a duty, associated with seeing a loved one suffer [28]. Influences affecting voluntary status, in Valapour et al.'s work, ran along a continuum ranging from persuasion to coercion [2, 17]. Studies have repeatedly shown that LDs with the highest degree of (presumably, external) pressure around decisionmaking also had the highest rate of regret, or at least 'unsureness' about whether they would choose to donate again [26-28].

Psychosocial providers and the ILDA evaluate whether a potential LD can choose to donate (or not) without inducement or fear of reprisal. Interviews elicit distinctions between internalized pressure and external pressure (coercion) that affects donor autonomy and safety. It is conceivable for a potential LD to disclose others' efforts at inducement, and his/ her own ability to make an autonomous decision about donation despite this pressure. If the prospective donor's experience of external pressure (or coercion) is affecting decisionmaking, however, transplant teams must assist with various options for stopping the donation process, with a variability in logistics noted in national surveys of practice. At the least, Thiessen et al. recommended that all prospective donors be offered a general statement regarding an 'unsuitability to donate' at any time [29••].

\section{Direct Payment}

As the organ shortage grows, concerns about organ sales, and exploitation, have climbed [9]. As outlined in the OPTN/UNOS living donor informed consent policy requirements, informed consent must include disclosure that "it is a federal crime for any person to knowingly acquire, obtain or otherwise transfer any human organ for valuable consideration (i.e., for anything of value such as cash, property, vacations)" [13••]. Prospective donors must agree to abide by these provisions. That said, risk of secondary gain as a driver for prospective LDs is notoriously difficult to assess accurately.

At first glance, it would appear that the challenge of assessing underlying motivation increases as more potential donors present to transplant centers without an emotional connection to their intended recipients (with motivation less likely to be centered around concern for a suffering loved one). The proportion of first-degree relatives as LDs continues to decline [30]. Whereas in 1989 only $8 \%$ of transplant programs would consider a non-directed donor (NDD), by 2007, $61 \%$ of responding programs evaluated NDDs [15]. However, and my own clinical practice seconds this, a Joint Societies consensus conference recommended that evaluation processes and structure fundamentally be the same for potential donors, regardless of relationship (or lack thereof) between donor and recipient [31]. In all cases, understanding of expectations between donor and recipient (including a lack of a financial relationship) should be agreed upon prior to proceeding. If areas of risk are identified, transplant teams may require the prospective donor to demonstrate sustained interest and coping with a prescribed 'cooling off' period, or seek consistency in the prospective donor's narrative history about motivation and expectations or between his/her desire to donate and other behavior (e.g., volunteer work).

\section{Methods of Assessing Understanding}

As is outlined in OPTN policies for living donor care, the LD must understand the evaluation process, the medical, surgical and psychosocial risks of living donation, and treatment options and expected outcomes of LDT for the recipient [13••]. Effective assessment of comprehension is crucial, given literature suggesting past LDs lacked adequate knowledge and understanding of risks $[4 \bullet \cdot, 16,17,19]$. Although CMS and OPTN requirements prescribe content elements, methods of education provision, and assessment of understanding, are not defined, and it is here there is room for growth in best practice standards.

Extant literature has focused on optimum ways to encourage people to consider living donation, and to learn basic facts about risk and process. Effective approaches include culturally competent education, home visits, web-based portals, and family-centered approaches [32-36]. However, few data support specific methods to communicate, and assess, a medically cleared potential LD's understanding of his/her risk profile and expected outcomes. Structured interview techniques help potential donors focus and reflect understanding back, a method that has been clearly supported in other fields of practice $[35,37]$. Some transplant programs have integrated knowledge testing prior to donation, though data about the impact and merit of this does not yet exist, and a validated tool has not yet been built-let alone one that can accommodate learning barriers and differences.

With or without a comprehension 'exam,' if the prospective donor has gaps in understanding, s/he should receive additional assessment, education, and intervention. Gaps in understanding may be attributed to cognitive deficits that preclude provision of informed consent; inadequate integration or 
understanding of risks/benefits; or evidence of significantly unrealistic expectations associated with donation. In many cases, an initial lack of understanding may not be a permanent contraindication to living donation, but can instead trigger additional consults, e.g., neurology or psychiatry, and/or tailored teaching to accommodate learning barriers (most often at our center, literacy limitations) [38].

It is also not uncommon for prospective living donors to voice that risks are of "no concern," that they want to donate "no matter what." Simmons and others, dating back to the 1970s and 1980s, found that LD decision making centers on moral, rather than deliberative, reasoning [39]. As such, part of the informed consent process is to assess whether prospective living donors have actually integrated risk information, and to help them slow down enough to process data, risks, and options.

In addition, psychosocial risk profile affects patients' ability to integrate understanding of risks. Some potential donors lack the maturity to identify themselves as vulnerable to risk (often associated with life stage) [40]; others demonstrate 'magical thinking' about what living donation will do for the intended recipient [41]. Each of these factors could be described as a relative contraindication or risk factor, warranting assessment and review.

\section{Specific Content Elements}

With several recent studies exploring the long-term impact of LD (and debate in the literature about implications of these data), content elements of informed consent should be expanded to include the evolving understanding of the risk of end-stage renal disease in LDs compared with healthy nondonors [42-46]. The prospective LD should learn about factors influencing donor medical and psychosocial risk variability (e.g., hypertension, body mass index, depression), and discuss implications for his/her specific risk profile [42-47]. The informed consent process should also include content about the potential impact of LD on future pregnancy [48, 49], factors influencing expected outcomes of the LDT [50, 51], as well as potential risks/benefits to not proceeding with donation, particularly in regard to the emotional impact of witnessing recipient health outcomes [52].

OPTN/UNOS policy mandates a separate informed consent process for the risks of the living donor evaluation itself. Although content elements are not prescribed, they should at least include description of the evaluation and donor candidacy process, the risk of identification of a health condition that precludes donation, and the risk that this diagnosis may affect insurability (rates and issuance). Additional content elements might include description of the transplant center's procedures in the event of discovery of misattributed paternity, a topic that has long been controversial in the transplant community, so clarification of policy would be helpful to communicate up front [53].

\section{Content Elements for Informed Consent Within Specific Living Donor Transactions}

Aspects of care for the non-directed LD and for the LD in paired donation warrant additional informed consent content elements. A 2013 Joint Societies Consensus Conference on Paired Kidney Donation outlined that, in these systems, donors should consent to risks specific to paired donation (e.g., a broken chain, or a kidney lost in transit) [54]. These donors (and especially bridge donors) should also consent to process differences (e.g., timing unpredictability; potential for additional testing) [55]. NDDs and LDs for paired exchange should be advised of confidentiality guidelines limiting information exchange about 'actual' recipient outcomes, particularly as this information has been linked to donor satisfaction $[24,54-57]$.

\section{Conclusions}

It is to be noted that the vast majority of living kidney donors, in the short- and long-term after donation, are glad they donated. Most prior donors describe the act of donation as profound, gratifying, and defining [24]. That said, predictors of struggle following LD include ambivalence, unexpected medical or financial consequences, and poor recipient health outcome. Each of these factors might be mitigated with robust decision-making aides and educational processes, and further research into best practice is warranted. Specifically, processes to support donor integration of risks should be validated (including the pros and cons of donor testing). Methods to help reluctant prospective donors stop the donation process (including the pros and cons of the so-called 'medicalout') should be explored, along with identifying the least traumatic ways to decline an enthusiastic prospective donor's candidacy [54]. And, perhaps ironically, standardized consent components should describe the variability in LD risk (especially when looking at the long-term consequences of living donation), and multidisciplinary teams at transplant centers should focus on helping prospective donors understand their specific risk profile.

\section{Compliance with Ethics Guidelines}

Conflict of Interest R.E. Hays declares that she has no conflict of interest.

Human and Animal Rights and Informed Consent This article does not contain any studies with human or animal subjects performed by any of the authors. 


\section{References}

Papers of particular interest and published recently are highlighted below as:

-• Of major importance

1. Beauchamp TL, Childress JF. Principles of biomedical ethics. 4th ed. New York: Oxford University Press; 1994.

2. Valapour M. The live organ donor's consent: is it informed and voluntary? Transplant Rev. 2008;22:196-9.

3. Council of the Transplantation Society. A report of the Amsterdam forum on the care of the live kidney donor: data and medical guidelines. Transplantation. 2005;29(6 Suppl):S53-66.

4.• Gordon EJ. Informed consent for living donation: a review of key empirical studies, ethical challenges and future research. Am J Transplant. 2012;12(9):2273-80. This review highlights challenges to each element of consent for living organ donors, and situates trends within broader policy contexts, debates, and avenues for future research.

5. Murray JE, Merrill JP, Harrison JH. Kidney transplantation between seven pairs of identical twins. Ann Surg. 1958;148:343-59.

6. Baker TB, Spicer HG. The history of living donor advocacy in living donor transplantation. In: Steel JL, editor. Living donor advocacy: an evolving role within transplantation. New York: Springer; 2014. p. 103-9.

7. Advisory Committee on Organ Transplantation to HHS. U.S. Department of Health and Human Services recommendations 118. http://organdonor.gov/legislation/acotrecs118.html. Accessed 26 Sep 2013.

8. Abecassis M, Adams M, Adams P, Arnold RM, Atkins CR, Barr ML, et al. Liver Organ Donor Consensus Group. Consensus statement on the live organ donor. JAMA. 2000;284(22):2919-26.

9. Pruett TL, Tibell A, Alabdulkareem A, Bhandari M, Cronin DC, Dew MA, et al. The ethics statement of the Vancouver Forum on the live lung, liver, pancreas, and intestine donor. Transplantation. 2006;81(10):1386-7.

10. Living Kidney Donor Follow-Up Conference Writing Group, Leichtman A, Abecassis M, Barr M, Charlton M, Cohen D, et al. Living kidney donor follow-up: state-of-the-art and future directions, conference summary and recommendations. Am J Transplant. 2011;11(12):2561-8.

11. Medicare Program; Hospital Conditions of Participation: Requirements for Approval and Re-Approval of Transplant Centers to Perform Organ Transplants; Final Rule. Federal Register. 2007;72(61). https://www.cms.gov/Medicare/ProviderEnrollment-and-Certification/CertificationandComplianc/ downloads/transplantfinal.pdf. Accessed 26 Sep 2013.

12. CMS Survey and Certification Letter: Organ Transplant Interpretive Guidelines. http://www.cms.gov/Medicare/Provider-Enrollmentand-Certification/SurveyCertificationGenInfo/downloads/ SCLetter08-25.pdf. Accessed 29 May 2014.

13.• Organ Transplantation and Procurement Network, Policy 14, Living Donation. http://optn.transplant.hrsa.gov/ContentDocuments/ OPTN Policies.pdf. Accessed 20 Jun 2014. These are the OPTN/ UNOS policies guiding current informed consent practices for living donors in the USA.

14. OPTN Living Donor Care checklist tools. http://optn.transplant. hrsa.bov/contentdocuments/living_donor_kidney_informed_ consent_checklist.doc. Accessed 26 Sep 2013.

15. Rodrigue JR, Pavlakis M, Danovitch GM, Johnson SR, Karp SJ, Khwaja K, et al. Evaluating living kidney donors: relationship types, psychosocial criteria, and consent processes at US transplant programs. Am J Transplant. 2007;7(10):2326-32.
16. Gordon EJ, Beauvais N, Theodoropoulos N, Hanneman J, McNatt $\mathrm{G}$, Penrod $\mathrm{D}$, et al. The challenge of informed consent for increased risk living donation and transplantation. Am J Transplant. 2011;11(12):2569-74.

17. Valapour M, Kahn JP, Bailey RF, Matas AJ. Assessing elements of informed consent among living donors. Clin Transplant. 2011;25(2):185-90.

18. Parekh AM, Gordon EJ, Garg AX, Waterman AD, Kulkarni S, Parikh CR. Living kidney donor informed consent practices vary between US and non-US centers. Nephrol Dial Transplant. 2008;23(10):3316-24.

19. Thiessen C, Kim YA, Formica R, Bia M, Kulkarni S. Written informed consent for living kidney donors: practices and compliance with CMS and OPTN requirements. Am J Transplant. 2013;13: 2713-21.

20. Steel JL, Dunlavy A, Friday M, Kingsley K, Brower D, Unruh M, et al. A national survey of independent living donor advocates: the need for practice guidelines. Am J Transplant. 2012;12(8):2141-9.

21. Steel JL, Dunlavy A, Friday M, Kingsley K, Brower D, Unruh M, et al. The development of practice guidelines for independent living donor advocates. Clin Transplant. 2013;27(2):178-84.

22. Hays, RE, LaPointe Rudow D, Dew MA, Taler SJ, Spicer H, Mandelbrot DA. The independent living donor advocate: a guidance document from the American Society of Transplantation's Living Donor Community of Practice (AST LDCOP.) Am J Transplant. 2015 (in press).

23. Toolbox Living Kidney Donation. Working group (WG) on Living donation under the EU "Action Plan on organ donation and transplantation (2009-2015): Strengthened Cooperation between Member States" http://www.slovenija-transplant.si/fileadmin/ Dokumenti/Porocila in nacrti/Living Donor Toolkit.pdf. Accessed 19 Nov 2014.

24. Dew MA, Zuckoff A, DiMartini AF, Dabbs AJ, McNulty ML, Fox KR, et al. Prevention of poor psychosocial outcomes in living organ donors: from description to theorydriven intervention development and initial feasibility testing. Prog Transplant. 2012;22(3):280-92.

25. Dew MA, Jacobs CL. Psychosocial and socioeconomic issues facing the living kidney donor. Adv Chronic Kidney Dis. 2012;19: 237-43.

26. Dew MA, DiMartini AF, DeVito Dabbs AJ, Zuckoff A, Tan HP, McNulty ML, et al. Preventive intervention for living donor psychosocial outcomes: feasibility and efficacy in a randomized controlled trial. Am J Transplant. 2013;13:2672-84.

27. Tong A, Chapman JR, Wong G, Kanellis J, McCarthy G, Craig JC. The motivations and experiences of living kidney donors: a thematic synthesis. Am J Kidney Dis. 2012;60(1):15-26.

28. Clemens K, Boudville N, Dew MA, Geddes C, Gill JS, Jassal V, et al. Donor Nephrectomy Outcomes Research (DONOR) Network. The long-term quality of life of living kidney donors: a multicenter cohort study. Am J Transplant. 2011;11(3):463-9.

29.• Thiessen C, Kim YA, Formica R, Bia M, Kulkarny S. Opting out: confidentiality and availability of an 'alibi' for potential living kidney donors in the USA. J Med Ethics. doi:10.1136/medethics-2014102184. This survey highlights the range in practice for prospective donors who opt out, and offers practical recommendations for best practice

30. Davis CL, Cooper M. The state of US living kidney donors. Clin J Am Soc Nephrol. 2010;5(10):1873-80.

31. Dew MA, Jacobs CL, Jowsey SG, Hanto R, Miller C, Delmonico FL. United Network for Organ Sharing (UNOS); American Society of Transplant Surgeons (ASTS); American Society of Transplantation (AST). Guidelines for the psychosocial evaluation of living unrelated kidney donors in the United States. Am J Transplant. 2007;7(5):1047-54. 
32. Ismail SY, Luchtenburg AE, Timman R, Zuidema WC, Boonstra C, Weimar W, et al. Home-based family intervention increases knowledge, communication and living donation rates: a randomized controlled trial. Am J Transplant. 2014;14(8):1862-9. doi:10.1111/ajt.12751.

33. Rodrigue JR, Cornell DL, Lin JK, Kaplan B, Howard RJ. Increasing live donor kidney transplantation: a randomized controlled trial of a home-based educational intervention. Am J Transplant. 2007;7(2):394-401.

34. Gordon EJ, Feinglass J, Martinez S, et al. A website for Hispanics/ Latinos about living donation and transplantation: a randomized controlled trial of increased knowledge. Am J Transplant. 2014;14(S3):479.

35. Gordon EJ, Caicedo JC, Ladner DP, Reddy E, Abecassis MM. Transplant center provision of education and culturally and linguistically competent care: a national study. Am J Transplant. 2010;10: 2701-7.

36. Garonzik-Wang JM, Berger JC, Ros RL, et al. Live donor champion: finding live kidney donors by separating the advocate from the patient. Transplantation. 2012;93:1147-50.

37. Fink A, Prochazka A, Henderson W, Bartenfeld D, Nyirenda C, Webb A, et al. Enhancement of surgical informed consent by addition of repeat back: a multicenter, randomized controlled clinical trial. Ann Surg. 2010;252:27-36.

38. Gordon EJ, Bergeron A, McNatt G, Friedewald J, Abecassis MM, Wolf MS. Are informed consent forms for organ transplantation and donation too difficult to read? Clin Transplant. 2012;26(2):275-83.

39. Simmons RG, Marine SK, Simmons RL. Gift of life: the effect of organ transplantation on individual, family and societal dynamics. New Brunswick: Transaction Publishers; 1987.

40. Campbell M, Wright L, Greenburg RA, Grant D. How young is too young to be a living donor? Am J Transplant. 2013;13:1643-9.

41. Hays RE. Contraindications to living donation from an ILDA perspective. In: Steel JL, editor. Living donor advocacy: an evolving role within transplantation. New York: Springer; 2014. p. 205-20.

42. Muzaale AD, Massie AB, Wang MC, Montgomery RA, McBride MA, Wainright JL, et al. Risk of end-stage renal disease following live kidney donation. JAMA. 2014;311:579-86.

43. Mjøen G, Hallan S, Hartmann A, Foss A, Midtvedt K, Øyen $\mathrm{O}$, et al. Long-term risks for kidney donors. Kidney Int. 2014;86:162-7.
44. Gaston RS, Matas AJ, McClellan W. A discussion of risk in living kidney donors. Timely topics in transplantation webinar series, AST. 2014 Apr 22 [archived online]. http://www.prolibraries.com/ trasnplant/?select=session\&sessionID=257. Accessed 15 May 2014.

45. Steiner RW, Ix JF, Rifkin DE, Gert B. Estimating risks of de novo kidney diseases after living kidney donation. Am J Transplant. 2014;14(3):538-44.

46. Gill JS, Tonelli M. Understanding rare adverse outcomes following living kidney donation. JAMA. 2014;311(6):577-9.

47. Lentine KL, Segev DL. Health outcomes among non-Caucasian living kidney donors: knowns and unknowns. Transpl Int. 2013;26(9):853-64.

48. Ibrahim HN, Akkina SK, Leister E, Gillingham K, Cordner G, Guo $\mathrm{H}$, et al. Pregnancy outcomes after kidney donation. Am J Transplant. 2009;9(4):825-34.

49. Garg AX, Nevis IF, McArthur E, Sontrop JM, Koval JJ, Lam NN, et al. the DONOR Network. Gestational hypertension and preeclampsia in living kidney donors. N Engl J Med. 2015;372(2): 124-33.

50. Rodrigue JR, Ladin K, Pavlakis M, Mandelbrot DA. Disclosing recipient information to potential living donors: preferences of donors and recipients, before and after surgery. Am J Transplant. 2011;11(6):1270-8.

51. Dubois JM, Iltis AS (ed.) Narrative symposium: living donation. Narra Inq Bioeth. 2012:2(1):1-54.

52. Allen MB, Abt PL, Reese PP. What are the harms of refusing to allow living kidney donation? An expanded view of risks and benefits. Am J Transplant. 2014;14(3):531-7.

53. Young A, Kim SJ, Gibner EM, Parikh CR, Harvat LD, Hizo-Abes $\mathrm{P}$, et al. Donor Nephrectomy Outcomes Research (DONOR) Network. Discovering misattributed paternity in living kidney donation: prevalence, preference, and practice. Transplantation. 2009;87(10):1429-35.

54. Melcher ML, Blosser CD, Baxter-Lowe LA, Delmonico FL, Gentry SE, Leishman R, et al. Dynamic challenges inhibiting optimal adoption of kidney paired donation: findings of a consensus conference. Am J Transplant. 2013;13(4):851-60.

55. Aull MJ, Kapur S. Kidney paired donation and its potential impact on transplantation. Surg Clin N Am. 2013;93:1407-21.

56. Fortin MC. Is it ethical to invite compatible pairs to participate in exchange programmes? J Med Ethics. 2013;39:743-7.

57. Sharif A. Unspecified kidney donation: a review of principles, practice, and potential. Transplantation. 2013;95(12):1425-30. 